\title{
Study of Fabricated Solar Dryer of Tomato Slices Under Jordan Climate Condition
}

\author{
Abdullah N. Olimat* \\ Fire Safety Engineering Department, Prince Al-Hussein Bin Abdullah II Academy of Civil Protection, Al-Balqa' Applied University \\ Jordan, P. O. Box: 30, Amman (11511), Jordan
}

\begin{abstract}
The objective of the current study was to investigate experimentally, the performance of a fabricated solar dryer under Jordan climate condition during the summer of 2013. The temporal variations of temperature difference between absorber plate and ambient temperature were obtained in the results and its influence on the performance of solar flat plate collector was examined. The effects of absorber plate temperature, ambient temperature and wind heat transfer coefficient on the top heat loss coefficient were also investigated. The results showed that the efficiency of the collector ranging between 45 to $66 \%$ which affected significantly by the amount of solar irradiation during the day. Only top heat loss was taken into considerations, since other losses were very small and might be negligible. Also the results confirmed that the performance of collector was maximum when the difference between plate and ambient temperatures was maximum. In addition, this work presented an indirect forced convection solar dryer, which consists of solar heater, fan and drying chamber. Fan was used to force the heated air through chamber to increase the drying rate. A 500 gram of tomatoes were dried to the final moisture content $28 \%$ from $95 \%$ (w.b). The experimental moisture ratios of the tomatoes were fitted to four mathematical drying models. Comparisons between these modes are sought using statistical analysis in the results. The fit quality obtained with each model was evaluated. After the comparison with the experimental obtained values, it was concluded that polynomial equation with second order represents the drying characteristics better than the other models by indicating high value of coefficient correlation $\left(\mathrm{R}^{2}=0.999564\right)$ and low values of other parameters( $\left.\boldsymbol{x}^{2}=0.000203 ; \mathrm{RMSE}=0.01011 ; \mathrm{MBE}=0.000102\right)$ compare with other models. The effective moisture diffusivity was estimated using Fick's second law and was $2.97 \times 10^{-7} \mathrm{~m}^{2} / \mathrm{s}$ with an average temperature of $306 \mathrm{~K}$.
\end{abstract}

Keywords: Moisture ratio; solar drying; moisture diffusivity;thin layer model; flat plate collector.

Article History: Received January $14^{\text {th }} 2017$; Received in revised form April 28 th 2017 ; Accepted June 10 ${ }^{\text {th }}$ 2017; Available online How to Cite This Article: Olimat, A.N. (2017) Study of Fabricated Solar Dryer of Tomato Slices Under Jordan Climate Condition. International Journal of Renewable Energy Development, 6(2), 93-101.

https://doi.org/10.14710/ijred.6.2.93-101

\section{Introduction}

Solar collector absorbs the incident solar radiation and converts it into thermal energy at the absorbing surface, which transfers the energy to air flowing through the collector. Flat plate collectors are designed for applications requiring moderate range of temperature which is less than $100{ }^{\circ} \mathrm{C}$. This range of drying air temperature is sufficient to drying the agricultural products. Drying agricultural products can be performed either using fossil fuels or exposing the products to the sun. But solar energy option is considered one of the promising alternative energy sources. The main advantages of solar energy over other sources are the availability in adequate quantity, free and environmentally clean.
Madhukeshwara and Prakash (2012) investigated the performance characteristics of solar flat plate collector with different selective surface coating. They reached a thermal efficiency of $76 \%$ for the collector of black chrome coating. They found that the performance of collector was influenced by selective coating and collector tilt angle. Sun drying exposes the products to solar radiation and the natural convection.

The advantages of sun drying are its low-priced and low-operational cost. On the other hand, there are several disadvantages for this method such as; the products will expose to the contamination and insect infestation also it is considered as a relatively slow process and time consuming (Esper and Mühlbauer, 1998).

\footnotetext{
* Corresponding author: olimat2012@gmail.com
} 
Solar drying method is a promising alternative to sun drying for drying the agriculture crops and vegetables with high quality dried product (Saleh and Badran, 2009). Solar energy is free, renewable and inexhaustible source in addition it is environmental friendly and economically. The main problems which faced solar drying are the reliability of solar radiation during rainy period or cloudy days and unavailability at night time.

In the drying method, amass and heat transfer occurs to remove water from the product by evaporation. The drying method of the product is divided into two stages. At the beginning the surface and centre of the product has the same amount of moisture. Firstly the water in the surface will be evaporated when it is heated by dry air at a constant rate. Secondly when the surface has dried, the moisture will be move from the centre to the surface of the product and then evaporated (Fournier and Guinebault, 1995)

Mustayen et al. (2014) presented the state of various kinds of solar dryer that were widely used and presented the new technologies that improve the existing solar dryer. They mentioned the indirect, direct, and mixed mode dryers that have been used in drying agricultural products in the tropical and subtropical countries. Also they identified the active and passive mode solar dryer.

Kabeel and Abdelgaied (2016) numerically investigated the effect of rotary desiccant wheel on the thermal performance of the solar dryer unit. The results show that, the temperature of drying air increased from $65{ }^{\circ} \mathrm{C}$ to $82^{\circ} \mathrm{C}$, while humidity ratio decreased from 15 to $8.8 \frac{\text { gwater }}{\text { Kg.dry air }}$ compared to the solar drying units without using a desiccant wheel at the same ambient condition. Furthermore, the percentage increase in the system useful heat gain for using the solar drying unit integrated with rotary desiccant wheel about $153 \%$ in average compared to the solar drying unit without rotary desiccant wheel.

Bagheri et al. (2013) experimentally studied the behavior of thin layer of tomato slices by using a laboratory solar dryer. The experimental data were fitted to nine drying mathematical models. The results show that, page model was the best model based on statistical parameters to predict the moisture content of the product during drying behaviour with high ability between drying thickness and air velocity.

Nabnean et al. (2016) experimentally studied the performance of hybrid solar dryer for drying osmotically dehydrated cherry tomatoes. The drying time for drying $100 \mathrm{~kg}$ of cherry tomatoes was 4 days. Also, the osmotically dehydrated cherry tomatoes were completely protected from insects, dust and rain, and dried products were in a good quality. The results show that, the pay-back period of the dryer was estimated to be 1.37 years and the solar collector efficiency was within the range of $21 \%-69 \%$.
Tunde-Akintunde (2011) studied experimentally the drying characteristics of chilli pepper by sun and solar drying. The experimental data were fitted to four thin-layer drying models (Newton, Henderson and Pabis, Logarithmic and Page). He found that the best model to describe the drying behaviour of sun and solar dried chilli pepper was Page model.

Afriyie et al. (2009) experimentally investigated the performance of a solar chimney for a direct mode dryer. They found that the solar chimney increased the airflow rate of a dryer which lead to improve the drying rate when the surrounding relative humidity of air was below a certain mark (60\% for cassava).

Dissa et al. (2009) designed, constructed and experimented validation of indirect solar dryer prototype of mango slices in the laboratory. Their results showed that three typical days of drying in harvest period of mango (May-June) were necessary to reach the range of water contents of conservation.

The objective of the current work is to examine the performance of solar flat plate collector and to examine the constructed indirect solar dryer of tomato slices under Jordan climate condition. Moreover, the experimental data and the moisture ratios, which will be obtained from solar dryer, will be validated using mathematical drying model.

\section{Description of solar dryer}

An experimental set-up of an indirect solar dryer unit was designed and constructed to investigate the efficiency of the system. The pictorial view and the schematic diagram of the solar dryer are shown in Fig. 1 and Fig. 2, respectively. It consists essentially of a solar collector, drying enclosure, trays, fan and chimney. The solar collector base (absorber) was lined with reflective sheet steel with $1 \mathrm{~mm}$ thickness which painted black to facilitate absorption of solar radiation and insulated with rock wool. While the top cover of solar collector which prevents dust and rain to contact with the absorber was made of a glass. The solar collector inclined at an angle of $30^{\circ}$ to the horizontal. The drying enclosure has a cross sectional area of 2500 $\mathrm{cm}^{2}$ with a height of $50 \mathrm{~cm}$. It constructed with highly polished wood isolated with rock wool to decrease the undesirable effects of temperature and humidity of air on drying experiment. The products were laid out inside the dryer on three rectangular trays which made of steel. Each tray was constructed of steel and mounted inside the enclosure. To enhance the flow of air the mean temperature in the drying chamber was $45{ }^{\circ} \mathrm{C}$. The entrance of the air was constructed with curve shape to make the flow of air more streamlined. The suction fan was installed at the outlet of air to increase the speed and the mass flow rate of the air that entered the unit. The bottom of chimney and the drying enclosure had the same cross sectional area. The chimney was designed and constructed to enhance the flow of air through the unit. The whole unit is supported by a metal frame to support the unit which 
located at $50 \mathrm{~cm}$ above the ground. The initial tomato mass was $500 \mathrm{~g}$ and the initial water content experimentally determined was $95 \%$ w.b and the thickness of tomato slices was $5 \mathrm{~mm}$.

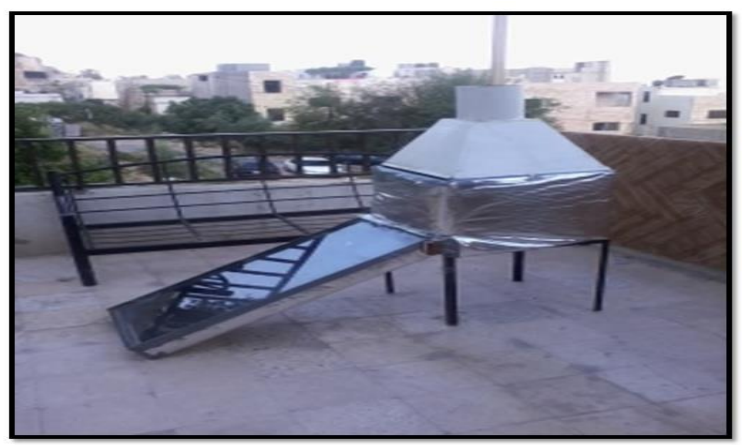

Fig. 1 Pictorial view of the solar dryer setup

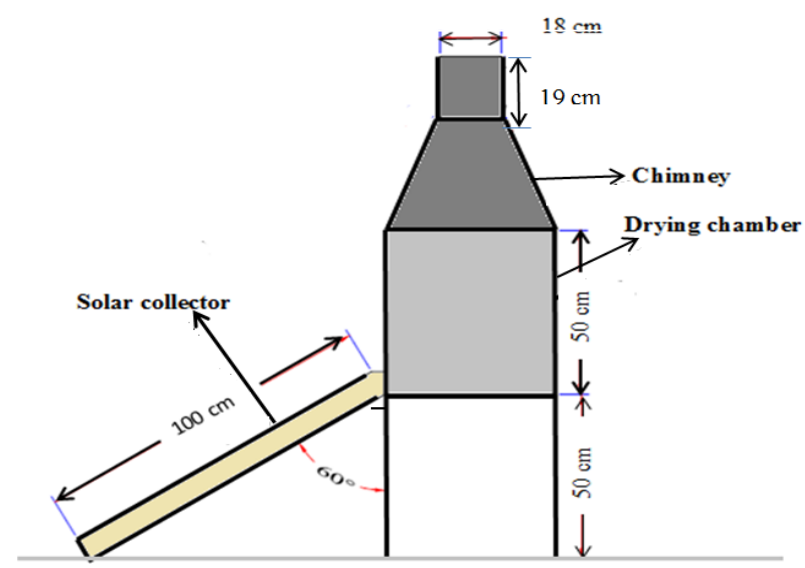

Fig. 2 Schematic diagram of the solar dryer unit

\section{Mathematical modeling}

\subsection{Theoretical analysis of solar air collector}

The performance of the solar collector flat plate depends on the amount of solar insulation absorbed by the plate. The major loss in the collector is from the top through the glass cover compared to the bottom and side loss. The top loss coefficient from the collector is evaluated by considering both convection and radiation from absorber plate to ambient. Overall heat loss coefficient, $U_{t}\left(\frac{\mathrm{w}}{\mathrm{m}^{2} \cdot{ }^{\circ} \mathrm{C}}\right)$ is representing the loss factor due to convection and radiation from absorbance. Other losses from edge and back of the collector are negligible. Under steady state condition the thermal heat loss ( $\left.\mathrm{Q}_{\mathrm{L}}\right)$ from absorber surface plate temperature $\left(\mathrm{T}_{\mathrm{s}}\right)$ and ambient temperature $\left(\mathrm{T}_{\mathrm{a}}\right)$ at collector surface area $\left(\mathrm{A}_{\mathrm{c}}\right)$ has the following form.

$\mathrm{Q}_{\mathrm{L}}=\mathrm{U}_{\mathrm{t}} \times \mathrm{A}_{\mathrm{c}} \times\left(\mathrm{T}_{\mathrm{s}}-\mathrm{T}_{\mathrm{a}}\right)$

To evaluate the top heat loss coefficient by taking into a consideration the convection and radiation from absorber plate in the upward direction. Farzad and
Emad (2012) correlated heat loss coefficient, Ut, as the following:

$\mathrm{U}_{\mathrm{t}}=\left[\frac{1}{\frac{\mathrm{C}}{\mathrm{T}_{\mathrm{s}}}\left[\frac{\left(\mathrm{T}_{\mathrm{s}}-\mathrm{T}_{\mathrm{a}}\right)}{(1+\mathrm{f})}\right]^{\mathrm{e}}}+\frac{1}{\mathrm{~h}_{\mathrm{w}}}\right]^{-1}+\frac{\sigma\left(\mathrm{T}_{\mathrm{s}}+\mathrm{T}_{\mathrm{a}}\right)\left(\mathrm{T}_{\mathrm{s}}^{2}+\mathrm{T}_{\mathrm{a}}^{2}\right)}{\frac{1}{\varepsilon_{\mathrm{S}}+0.0059 \mathrm{~h}_{\mathrm{w}}}+\frac{1+\mathrm{f}+0.133 \varepsilon_{\mathrm{S}}}{\varepsilon_{\mathrm{g}}}-1}$

The following parameters are used in Eq. (2)

$\mathrm{f}=1.07866\left(1+0.089 \mathrm{~h}_{\mathrm{w}}-0.1166 \mathrm{~h}_{\mathrm{w}} \varepsilon_{\mathrm{s}}\right)$

$\mathrm{C}=520\left(1-0.00005 \beta^{2}\right)$

$\mathrm{e}=0.430\left(1-\frac{100}{\mathrm{~T}_{\mathrm{S}}}\right)$

Where $\boldsymbol{\beta}$ is the collector tilt angle in degree and $\varepsilon_{\mathrm{s}}$ and $\varepsilon_{\mathrm{g}}$ are absorber and glass cover emissivity, respectively.

Kumar and Mullick (2010) mentioned the convective heat transfer coefficient, $h_{w}$, for air flowing over the outside surface of the glass cover as following formula:

$\mathrm{h}_{\mathrm{w}}=5.7+3.8 \times \mathrm{V}_{\mathrm{w}}$

Where, $\mathrm{V}_{\mathrm{w}}$ is the wind speed in $\mathrm{m} / \mathrm{s}$.

The amount of solar radiation received by the collector, $\mathrm{E}_{\mathrm{i}}$, is written as

$\mathrm{E}_{\mathrm{i}}=\mathrm{I} \times \mathrm{A}_{\mathrm{C}}$

Where I is the intensity of solar radiation, $\frac{\mathrm{w}}{\mathrm{m}^{2}}$, incident on the aperture plane of the solar collector.

Part of radiation incident on the collector is reflected back to the sky and absorbed by the glazing; the remaining is transmitted through the glazing and reaches to the absorber. So the amount of radiation received by the absorber, $Q_{i}$, is given in Eq.(5) (Farahat et al. 2008).

$\mathrm{Q}_{\mathrm{i}}=\mathrm{I} \times \mathrm{A}_{\mathrm{C}} \times \tau \times \alpha$

Where $\alpha$ and $\tau$ are, respectively, the solar absorbance and transmittance of the glass.

Ramadhani et al. (2014) expressed the rate of useful energy gain $Q_{u}$, collected to solar energy input on the collector as following:

$\mathrm{Q}_{\mathrm{u}}=\mathrm{Q}_{\mathrm{i}}-\mathrm{Q}_{\mathrm{L}}$

The collector thermal efficiency $\left(\eta_{c}\right)$ is defined as the ratio of useful energy gain to the incident solar energy and it expressed as shown

$\eta_{c}=\frac{\int Q_{u} d t}{A_{c} \times \int I d t}$

\subsection{Mathematical modeling of drying curves}

Many theoretical and empirical models are reported in literature which described the drying. The use of curve fitting to describe the scattered 
experimental data is widespread in all fields. The aim of this analysis is to standardize the scatter data into a uniformly recognized form. The moisture ratio (MR) of the tomatoes was calculated by using Eq. (8) (Doymaz and İsmail, 2011).

$M R=\frac{M_{t}-M_{e}}{M_{o}-M_{e}}$

Where, $\mathrm{M}_{\mathrm{t}}, \mathrm{M}_{\mathrm{o}}$ and $\mathrm{Me}$ are the moisture content at any time, initial moisture content , and equilibrium moisture of dying in $\left(\frac{\mathrm{Kg} \text { water }}{\mathrm{kg} \text { dry solid }}\right.$, respectively.

The products were not exposed to a uniform relative humidity and temperature continuously also the values of $\mathrm{M}_{\mathrm{e}}$ are relatively small compared to $\mathrm{M}_{\mathrm{t}}$ or $\mathrm{M}_{\mathrm{o}}$, hence Eq. (8) was simplified as shown in Eq.(9) (Doymaz , 2007; El-Beltagy et al. 2007).

$\mathrm{MR}=\frac{\mathrm{M}_{\mathrm{t}}}{\mathrm{M}_{\mathrm{o}}}$

Experimental data of drying curves of tomatoes were fitted by means of four thin-layer drying moisture ratio models which are widely used. The aim of fitting was to select the suitable model for describing the drying characteristics of tomatoes. These models were Henderson and Pabis, Lewis, logarithmic models and Wang and Singh.

These models are derived by simplifying the general series solution of Fick's second law. Henderson and Pabis (1961) model presented the first term of a general series solution of Fick's second law which modeled the thin-layer drying characteristics of various agricultural products as following.

$M R=a \times e^{-k t}$

Where a and $\mathrm{k}$ are drying constant, $\mathrm{t}$ is the drying time in hours.

Lewis model is a special case of Henderson and Pabis model where intercept is unity. It was used to describe the grapes seed as shown in Eq. (11) (Johan et al. 2008).

$\mathrm{MR}=\mathrm{e}^{-\mathrm{kt}}$

The third model used in this work was logarithmic model as shown in Eq. (12) which is widely used for thin-layer drying fields (Gagan et al. 2008).

$\mathrm{MR}=\mathrm{a}+\mathrm{b} \ln \mathrm{t}$

Wang and Singh model was used to describe the characteristics behavior of drying rough rice (Wang and Singh, 1978) as shown in Eq.(13).

$\mathrm{MR}=\mathrm{bt}^{2}+\mathrm{at}+1$
The current study adopted the second order polynomial model in form of Eq. (14) to validate experimental data.

$\mathrm{MR}=\mathrm{bt}^{2}+\mathrm{at}+\mathrm{c}$

Where $a, b$, and c are drying coefficients.

The first term of series of the solution of Fick's diffusion equation for long drying periods of solid objects (dried tomatoes slices) with slab geometry was applied to the experimental data to calculate the effective moisture diffusivity as shown in Eq. (14) (Maskan et al. 2002)

$$
M R=\frac{8}{\Pi^{2}} e^{-\left(\frac{-\Pi^{2} D_{\text {eff }} \mathrm{t}}{4 \mathrm{~L}^{2}}\right)}
$$

The diffusion coefficient which is the slope of experimental drying data in terms of $\ln (\mathrm{MR})$ versus drying time were used to calculate the effective diffusivity of tomatoes as cleared in Eq. (15) (Doymaz, 2004).

$$
\text { Slope }(\mathrm{k})=\frac{\mathrm{D}_{\mathrm{eff}} \Pi^{2}}{4 \mathrm{~L}^{2}}
$$

The use of regression analysis which describes experimental data as a mathematical form is necessary to standardize data interpretation into a uniformly recognized form. Correlation index $\left(\mathrm{R}^{2}\right)$, the reduced chi-square $\left(\chi^{2}\right)$, root mean square error (RMSE) and mean bias error (MBE) were performed to evaluate the bitter fit which means the more accurately the function describes the data.

The correlation index or coefficient of determination is defined as (Angus, 2001)

$\mathrm{R}^{2}=1-\frac{\sum\left(\mathrm{MR}_{\mathrm{e}, \mathrm{i}}-\mathrm{MR}_{\mathrm{pi}}\right)^{2}}{\sum\left(\mathrm{MR}_{\mathrm{e}, \mathrm{i}}-\mathrm{MR}_{\text {mean }}\right)^{2}}$

Where $\mathrm{MR}_{\mathrm{e}, \mathrm{i}}, \mathrm{MR}_{\mathrm{p}, \mathrm{i}}$ and MRmean are the experimental, predictable values and mean data of moisture ratio, respectively

The reduced chi-square, root mean square error, and mean bias error correlations were used to select the best model (goodness of fit data) to account the variation of dried products. The statistical correlation of those indicators was calculated according to Eqs. (17-19), respectively (Osama et al. 2001; Tunde 2010).

$$
\begin{aligned}
& \chi^{2}=\frac{\sum_{\mathrm{i}=1}^{\mathrm{N}}\left(\mathrm{MR}_{\mathrm{e}, \mathrm{i}}-\mathrm{MR}_{\mathrm{p}, \mathrm{i}}\right)}{\mathrm{N}-\mathrm{m}} \\
& \mathrm{RMSE}=\left[\frac{\sum_{\mathrm{i}=1}^{\mathrm{N}}\left(\mathrm{MR}_{\mathrm{p}, \mathrm{i}}-\mathrm{MR}_{\mathrm{e}, \mathrm{i}}\right)}{\mathrm{N}}\right]^{\frac{1}{2}} \\
& \mathrm{MBE}=\frac{\sum_{\mathrm{i}=1}^{\mathrm{N}}\left(\mathrm{MR}_{\mathrm{p}, \mathrm{i}}-\mathrm{MR}_{\mathrm{e}, \mathrm{i}}\right)}{\mathrm{N}}
\end{aligned}
$$


Where $\mathrm{m}$ is the number of drying constant, and $\mathrm{N}$ is number of observation.

\section{Results and discussion}

\subsection{Solar radiation and performance of solar} collector

Solar dryer is a renewable energy mechanism which can solve the problems of excess vegetables without using high grades of energy. An overview has been given in this work to explain the principle and mechanism of operation. The experimental investigations were conducted using the designed system shown in Fig. 1 and Fig. 2. The design parameters for flat plate solar collector are cleared in Table 1. Fig. 3 illustrates the temporal variations of the measured overall solar radiation and ambient temperature for a typical summer day (30 August 2013) which was employed for calculations. It can be observed in Fig. 3 that the irradiance and ambient temperature are varied between 70 and $930 \mathrm{~W} / \mathrm{m}^{2}$ and $21-40^{\circ} \mathrm{C}$ respectively. The time variation of heat is of low values before and after the midday. It is maximum values occurred at solar midday (12:00).

Table 1.

Design parameters of flat plate solar collector

\begin{tabular}{lc}
\hline Parameter & Value \\
\hline Absorbance of glass $(\boldsymbol{\alpha})$ & 0.97 \\
Transmittance of glass $(\boldsymbol{\tau})$ & 0.765 \\
Emissivity of the glass $\left(\boldsymbol{\varepsilon}_{\mathrm{g}}\right)$ & 0.84 \\
Emissivity of the absorber $\left(\boldsymbol{\varepsilon}_{\mathrm{s}}\right)$ & 0.92 \\
Tilt angle of collector $(\boldsymbol{\beta})$ & $30^{\circ}$ \\
Wind speed $\left(\mathrm{V}_{\mathrm{w}}\right)$ & $2.0 \mathrm{~m} / \mathrm{s}$ \\
Stefan Boltzmann constant $(\boldsymbol{\sigma})$ & $5.67 \times 10^{-8} \mathrm{~W} / \mathrm{m}^{2} . \mathrm{K}^{4}$ \\
\hline
\end{tabular}

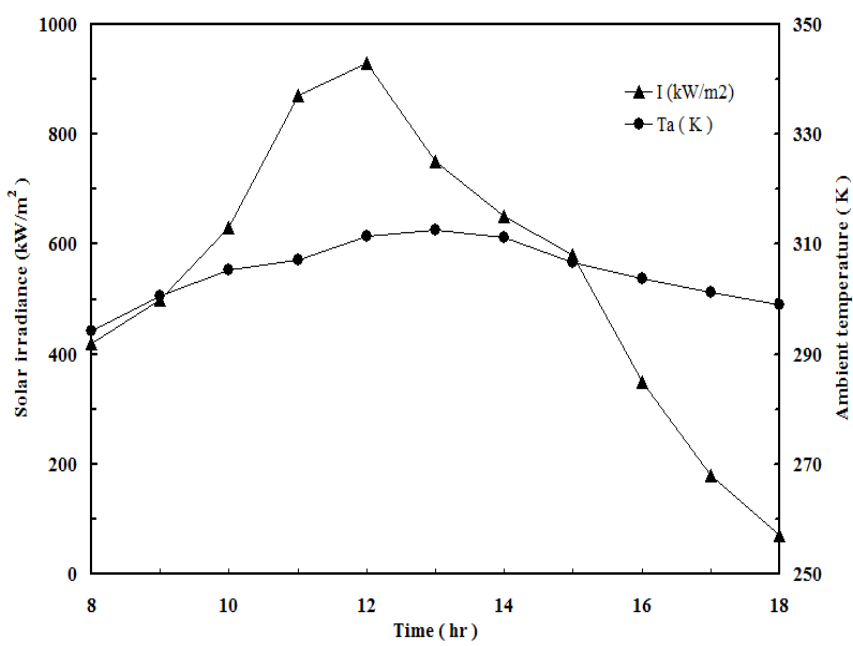

Fig. 3 Historical variation of solar radiation and ambient temperature of a typical day during summer (30 August 2013).

Energy analysis was carried out to evaluate the thermal efficiency of the constructed solar collector. Experimental study and measurements were performed to investigate the suitability and effectively of the selected material used in the construction of solar system.

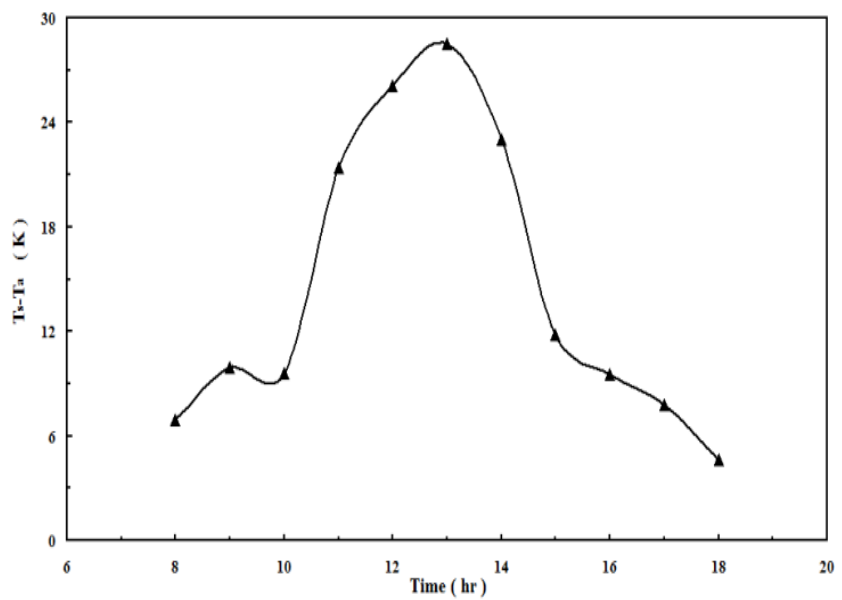

Fig. 4 Variation in temperature difference between absorber and ambient temperature.

The temporal variations of temperature difference between ambient and absorber temperatures are measured during the experiments and plotted in Fig. 3. The variations in temperature difference are due to the fluctuations of solar irradiance. The maximum difference occurred during the period $12: 00$ to $14: 00$ at the maximum solar irradiance period.

The overall top heat loss is a function of several parameters which include temperature of the absorber plate, glass cover and ambient, emissivity of the absorber and glass cover, spacing between the absorber plate and glass cover, tilt angle of the collector, wind speed. The top loss coefficient from collector is estimated by taking into account both convection and radiation from absorber plate to ambient and calculated according to Eq. (2). The influence of top heat loss coefficient versus temperature difference between absorber and ambient was calculate and plotted as shown in Fig. 4 and Fig. 5.

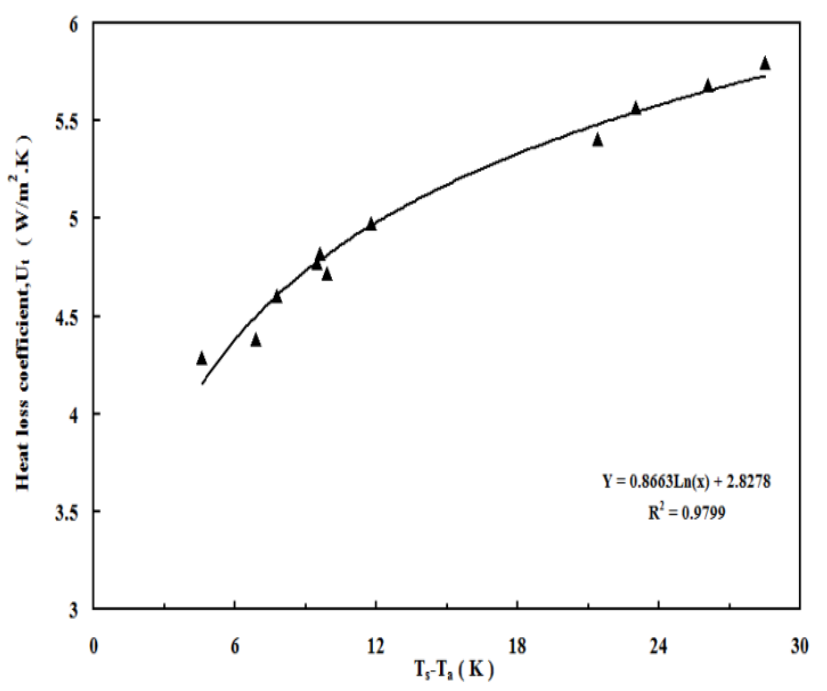

Fig. 5 Variation of heat loss coefficient versus temperature difference between absorber and ambient. 


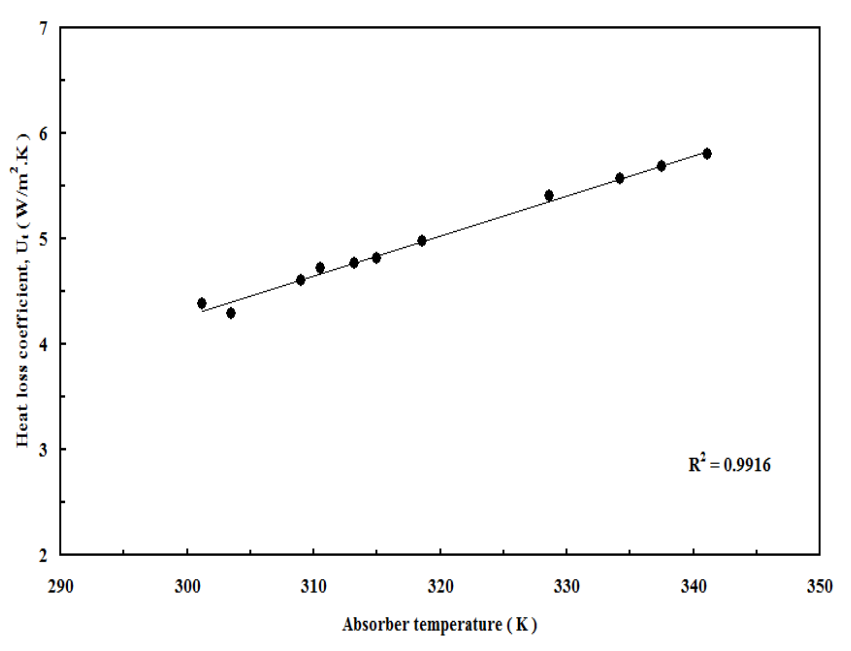

Fig. 6 Variation of heat loss coefficient versus absorber temperature.

The collector efficiency versus $\frac{\left(\mathrm{T}_{\mathrm{S}}-\mathrm{T}_{\mathrm{a}}\right)}{\mathrm{I}}$ has been measured and plotted as shown in Fig. 5 at wind speed $2.0 \mathrm{~m} / \mathrm{s}$, tilt angle $30^{\circ}$ and variable ambient temperature during the day of experiment. The absorber of the collector made from steel sheet with thickness $4 \mathrm{~mm}$ and painted with an inexpensive material whose absorbance $\left(\alpha_{\mathrm{s}}=0.97\right)$ and emissivity $\left(\varepsilon_{\mathrm{s}}=0.84\right)$. The glass cover has emissivity $\left(\varepsilon_{\mathrm{g}}=0.84\right)$ and transparent $\left(\tau_{\mathrm{g}}=0.765\right)$. The results confirm the expected performance is maximum when the temperature difference between absorber temperature and ambient is maximum. When the temperature difference is equal zero the maximum efficiency achieved is called optical efficiency. The efficiency of the collectors is ranges from $45 \%$ to $66 \%$ during the day. The efficiency of flat plate collector is found to increase with increasing ambient temperature due to decreasing of heat loss from the system. The slope of line represents the rate of heat loss from collector.

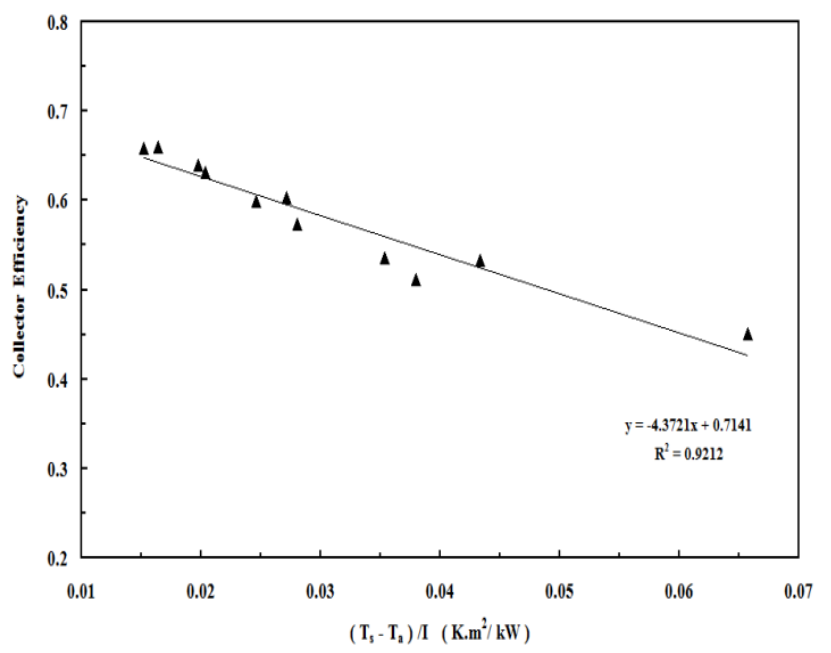

Fig. 7 Thermal efficiency versus $\frac{\left(\mathrm{T}_{\mathrm{s}}-\mathrm{T}_{\mathrm{a}}\right)}{\mathrm{I}}$ variations of flat plate collector for $\boldsymbol{\beta}=30^{\circ}$ and $\mathrm{V}_{\mathrm{w}}=2.0 \mathrm{~m} / \mathrm{s}$.

\subsection{Experimental validation of the solar drying model}

The experiments were carried out during 3 to 6 September 2013 from 8:00 am to 6:00 pm. The experiments were carried out within the range of ambient air temperatures from 294.4 to $314.2 \mathrm{~K}$ and the drying air temperature varied between 296.3 and $317.2 \mathrm{~K}$. The historical variations of ambient temperature and drying air temperature during the test are shown in Fig. 8. Tomato was cut into a uniform slices with approximately $5 \mathrm{~mm}$ thickness by around $8 \mathrm{~cm}$ diameter. The initial average moisture content of tomatoes was about $95 \%$ (w.b). The results showed the average temperature difference between drying air and ambient temperatures were 2.98, 2.45, 2.3 and 2.5 respectively during the day of experiment. It is observed that, the values of temperature temperatures were close to each other, which indicate that the resistance to external transfer is constant and rate of water evaporation on the surface of the product was constant relatively. Water transport mechanism of the product is relatively limited by the external transfer.

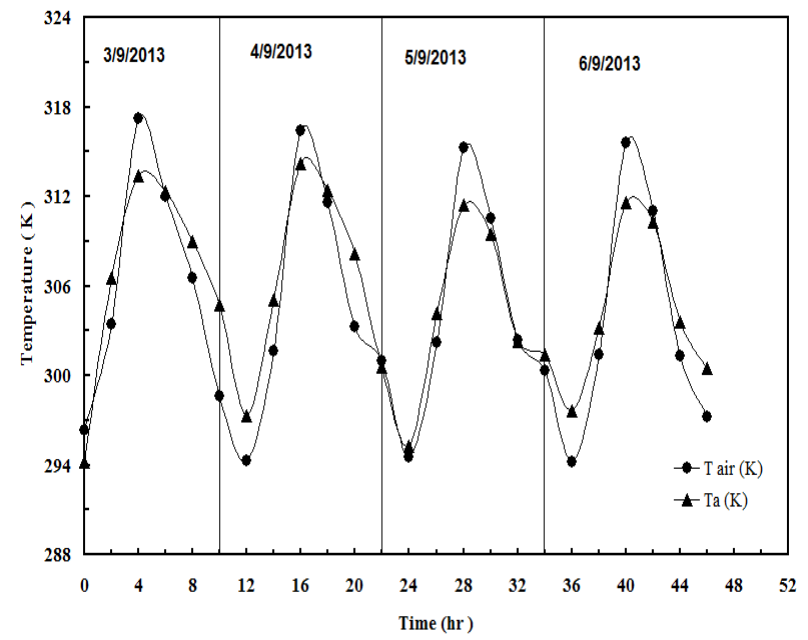

Fig. 8 Temporal variation of ambient air temperature and drying air temperature of solar dryer during the days of test.

The drying data obtained from experiments were flitted to four thin-layer models which mentioned in the theoretical background section. The four thin-layer models were evaluated and compared in terms of the statistical parameters $\mathrm{R}^{2}, \boldsymbol{x}^{2}$, RMSE and MBE. The statistical analysis values were summarized in Table 2 . $\mathrm{R}^{2}$ is considered to be one of the best correlations used to select the best equation for variation in the solar drying curves. The $\mathrm{R}^{2}$ value calculated is designed to give a better correlation between the moisture ratio and drying time. It represents the fraction of the overall variance of the dependent variable to the independent variable. All cases gave consistently high values of $R^{2}$ in the range from 0.930463 to 0.999564 . This indicates that all models could satisfactorily describe the solar drying rates of tomato. The $\boldsymbol{x}^{2}$ values 
varied between 0.000203 and 0.0017 , RMSE values between 0.01011 and 0.14345 , and $\mathrm{MBE}$ values between 0.000102 and 0.020578. Generally, second order polynomial model gave a higher $\mathrm{R}^{2}$ and lower $\boldsymbol{x}^{2}$, RMSE and MBE values as shown in Table 2. From the results tabulated, polynomial with second order gave the best results than other models to describe the drying characteristics of tomatoes at $55-70{ }^{\circ} \mathrm{C}$.

Table 2.

\begin{tabular}{|c|c|c|c|c|c|}
\hline Model & Model constant & $\mathbf{R}^{2}$ & $\boldsymbol{x}^{2}$ & RMSE & MBE \\
\hline $\begin{array}{c}\text { Handerson and } \\
\text { Pabis }\end{array}$ & $\begin{array}{l}\text { a: } 0.995968 \\
\text { k: }-0.02370\end{array}$ & 0.995968 & 0.0017 & 0.14345 & 0.020578 \\
\hline Lewis & $\mathrm{k}:-0.02595$ & 0.997239 & 0.001149 & 0.121895 & 0.014858 \\
\hline logarithmic & $\begin{array}{l}\text { a: } 0.9973 \\
\text { k:- } 0.1086\end{array}$ & 0.930463 & 0.030533 & 0.336615 & 0.11331 \\
\hline $\begin{array}{c}\text { Polynomial second } \\
\text { order }\end{array}$ & $\begin{array}{l}\text { a: } 0.000017 \\
\text { b:- } 0.01729 \\
\text { c: } 0.947353\end{array}$ & 0.999564 & 0.000203 & 0.01011 & 0.000102 \\
\hline
\end{tabular}

Curve fitting criteria for thin-layer drying model for drying tomatoes

Fig. 9 compares the variations of experimental and predicated moisture ratios by using Wang model for tomatoes with drying time. According to the Fig. 8, the data banded around straight line, $\mathrm{R}^{2}=0.996$, which showed the suitability and good agreement of second order model in describing the drying behavior of tomatoes.

A simplified mathematical Fick's second equation of diffusion was used to estimate the effective diffusivity of tomato slices during drying period. The effective diffusivity was estimated by plotting the variation of $\ln (\mathrm{MR})$ versus drying time as shown in Fig. 10 . The relation is straight line with slope 0.0293 . Using the slope of the curve and implemented in Eq. (3). The estimated value of effective diffusivity of tomato slices was $2.97 \times 10^{-7} \frac{\mathrm{m}^{2}}{\mathrm{~s}}$ at the average drying air $306 \mathrm{~K}$ and drying air velocity $2.0 \mathrm{~m} / \mathrm{s}$.

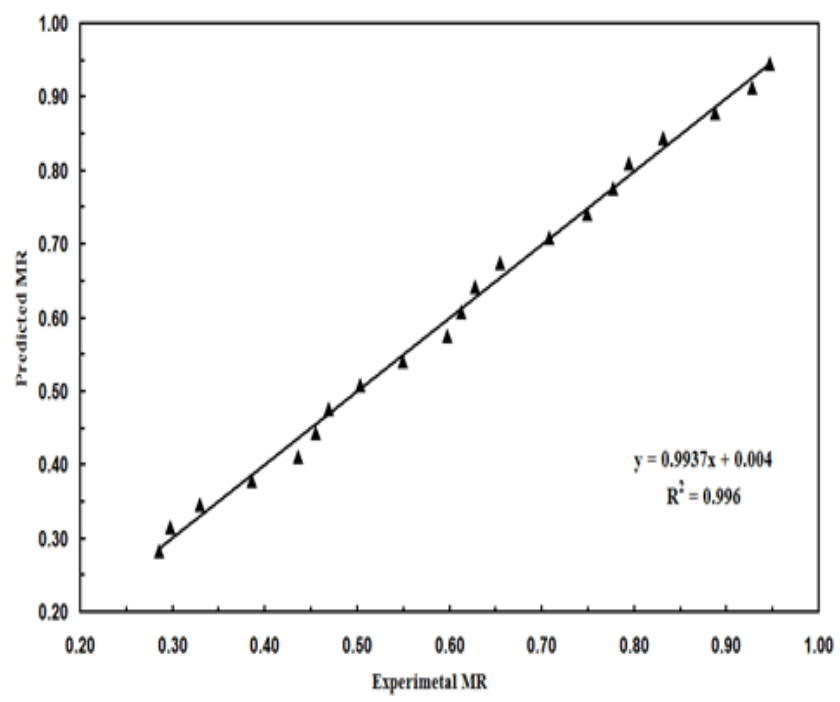

Fig. 9 Variation of experimental and predicted moisture ratio by the second order polynomial model with drying time.

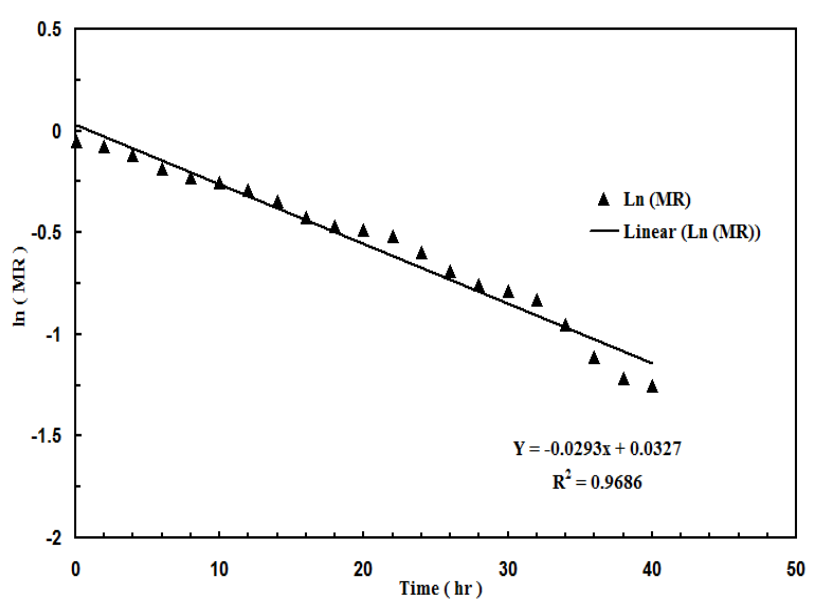

Fig. 10 Variation of $\ln (M R)$ with the drying time

Fig.11 showed the temporal variation of weight loss of tomato slices during the period of drying. The weight loss decreases as the drying time increases, until reached finally 160.5 gram. The moisture content of the product will also decrease with decrease mass loss. It is significant to determine the mass shrinkage ratio (MSR) of the drying product. The mass shrinkage ratio during the period of drying was determined according to the following formula:

$$
\operatorname{MSR}=\left[1-\frac{\mathrm{w}_{\mathrm{t}}}{\mathrm{w}_{\mathrm{O}}}\right]
$$

Where $\mathrm{W}_{\mathrm{t}}$ and $\mathrm{W}_{\mathrm{o}}$ denote the initial weight of product (gram) and weight of product at any time $\mathrm{t}$ (gram), respectively.

The MSR was calculated after measuring the mass of slices before and after drying every two hours. Data analysis showed that the MSR decreased with decrease of dried sample and with increased 
irradiation. The maximum MSR reached at the end of drying was about 0.679 . The figure indicates that, a linear relationship between MSR with time.

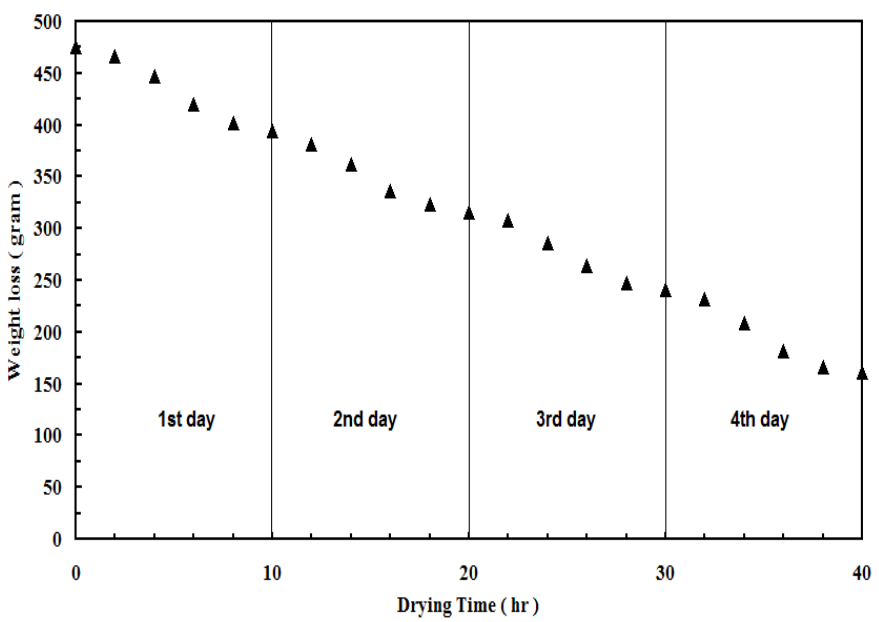

Fig. 11 Hourly variation of weight loss of tomato slices during the period of drying.

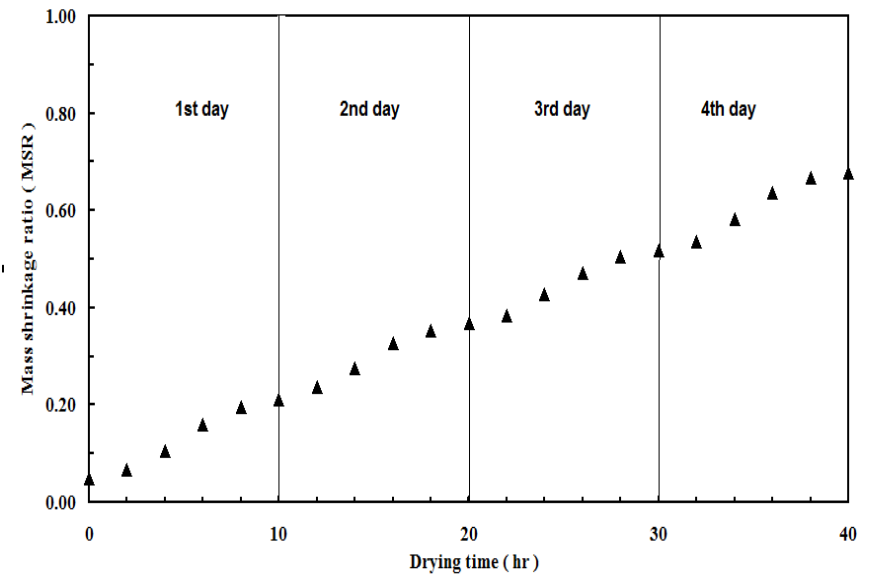

Fig. 12 Temporal variation of mass shrinkage ratio of the tomato.

\section{Conclusions}

A study on a performance of solar flat plate collector under Jordan weather condition during the summer 2013 was successfully examined. The performance of solar collector to heat the drying air ranged between 45 to $66 \%$ during the day when the irradiance and ambient temperature were varied between 70 and 930 $\mathrm{W} / \mathrm{m}^{2}$ and $21-40^{\circ} \mathrm{C}$ respectively. Solar dryer with an indirect forced convection solar dryer was installed to dry thin layer slices of tomatoes. Electrical fan was used in the apparatus to force the heated air though the dryer chamber to increase the drying rate. The initial moisture ratio of tomatoes was $95 \%$ (w.b) and dried until reached $28 \%$. The obtained experimental moisture ratio was compared with four mathematical models in order to predict the thin layer drying behavior of the dried product. Models were evaluated and compared in terms of the statistical parameters $\mathrm{R}^{2}$, $\boldsymbol{x}^{2}, \mathrm{RMSE}$ and MBE. Wang model gave the best results than other models to describe the drying characteristics of tomatoes at $55-70{ }^{\circ} \mathrm{C}$. The results showed that all cases gave consistently high value $\mathrm{R}^{2}$ in the range from 0.930463 to 0.999564 which indicated that all models could be satisfactorily to describe the solar drying rates of tomato. Polynomial with second order was found to be a better model for describing the drying behavior of tomatoes than the other models since it gave a higher $\mathrm{R}^{2}$ and lower $\chi^{2}, \mathrm{RMSE}$ and MBE values.

\section{Nomenclature}

$\begin{array}{ll}\text { A } & \text { Area, m2 } \\ \mathrm{a}, \mathrm{b}, \mathrm{c}, \mathrm{k}, \mathrm{n} & \text { Constants in the drying models } \\ \text { Deff } & \text { Moisture diffusivity, m2/s } \\ \mathrm{E} & \text { Solar radiation, } \mathrm{kW} \\ \mathrm{h} & \text { Heat transfer coefficient of air, W/m2.K } \\ \mathrm{I} & \text { Intensity solar radiation, } \mathrm{kW} / \mathrm{m} 2 \\ \mathrm{~L} & \text { Thickness of slices, } \mathrm{mm} \\ \mathrm{m} & \text { Number of drying constant } \\ \mathrm{MBE} & \text { Bias mean error } \\ \mathrm{MR} & \text { Moisture ratio } \\ \mathrm{M} & \text { Moisture content, Kg water } / \mathrm{kg} \text { dry solid } \\ & \text { Mass shrinkage ratio } \\ \mathrm{MSR} & \\ \mathrm{N} & \text { Number of observation } \\ \mathrm{Q} & \text { Rate of heat, W } \\ \mathrm{R}^{2} & \text { Correlation index } \\ \mathrm{RMSE} & \text { Root mean square error } \\ \mathrm{t} & \text { Time, minute } \\ \mathrm{T} & \text { Temperature, Kelvin } \\ \mathrm{U} & \text { Overall heat loss coefficient, } \frac{\mathrm{w}}{\mathrm{m}^{2}{ }^{\circ} \mathrm{C}} \\ \mathrm{V} & \text { Wind speed, m/s } \\ \boldsymbol{\varkappa}^{2} & \text { Reduced chi-square } \\ \mathrm{w} . \mathrm{b} & \text { Wet basis } \\ & \end{array}$

Greek symbols

$\begin{array}{ll}\boldsymbol{\beta} & \text { Collector tilt angle, degree } \\ \boldsymbol{\sigma} & \text { Stefan- Boltzman constant, W/m2.K4 } \\ \varepsilon & \text { Emissivity } \\ \boldsymbol{\alpha} & \text { Solar absorbance of glass } \\ \boldsymbol{\tau} & \text { Transmittance of glass } \\ \boldsymbol{\eta} & \text { Collector thermal efficiency }\end{array}$

Sub script

Ambient
Collector
Equilibrium
Received
Loss
Glass
Initial
Predicted
Absorber plate
Top




\section{References}

Afriyie, J. K., Nazh, M. A. A., Rajakaruna, H.and Forson. F. K. (2009). Experimental investigations of a chimney dependent solar crop dryer. Renewable energy, 34, 217-222.

Angus, M. B. (2001) A step-by-step guide to non-linear regression analysis of experimental data using a Microsoft Excel spread sheet. Computer Methods and Programs in Biomedicine, 65,191-200.

Bagheri, H., Arabhosseini, A., Kianmehr, M.H. and Ghegini. G.R. (2013) Mathematical modeling of thin layer solar drying of tomato slices. Agric Eng Int, CIGR Journal, 15(1), 146-153.

Dissa, A. O., Bathiebo, J., Kam , S., Savadogo, P. W.,Desmorieux, H. and Koulidiati. J. (2009) Modelling and experimental validation of thin layer indirect solar drying of mango slices. Renewable energy, 34, 1000-1008.

Doymaz, İ and Osman, İ. (2011) Drying characteristics of sweet cherry. IChemE , 89, 31-38.

Doymaz, İ. (2004) Pretreatement effect on sun drying of mulberry fruits. Journal of food engineering, 65(2), 205-209.

Doymaz, İ. (2007) Air-drying characteristics of tomatoes. Journal of food engineering, 78, 1291-1297.

El-Beltagy, A., Gamea, G. R. and Amer Essa. A. H. (2007) Solar drying characteristics of strawberry. Journal of food engineering, 78, 456-464.

Esper, A., and Mühlbauer. W. (1998) Solar drying-an effective means of food preservation. Renewable energy, 15(1-4), 95100.

Farahat, S., Sarhaddi, F. and Ajam. H. (2008) Exergetic optimization of flat plate solar collectors. Renewable energy, 34(4), 1169-1174.

Farzad, J. and Emad, A. (2012) Energetic and exergetic evaluation of flat plate solar collectors. Renewable energy, $56,55-63$.

Fournier, M., and Guinebault A. (1995) The "shell" dryer modeling and experimentation. Renewable energy, 6(4), 459-463.

Gagan, D.S., Rajiv , S., Bawa., A. S. and Saxena. D. C. (2008) Drying and rehydration characteristics of water chestnut (Trapa natans) as a function of drying air temperature. Journal of food engineering, 87, 213-221.

Henderson, S. M., and Pabis, S. (1961) Grin drying theory II: Temperature effects on drying coefficients. Journal of agricultural engineering research, 6,169-174.

Johan, S. R., David, R. K. and Olga, P.Z. (2008) Drying kinetics of grapes seed. Journal of food engineering 89, 460-465.

Kabeel, A. E., and Abdelgaid, M. (2016) Performance of novel solar dryer. Process safety and environmental protection, 102, 183-189.

Kumar, S., and Mullick S. C. (2010) Wind heat transfer coefficient in solar collectors in outdoor conditions. Solar energy, 84(6), 956-963.

Madhukeshwara, N., and Prakash. E. S. (2012) An investigation on the performance characteristics of solar flat plate collector with different selective surface coatings. International journal of energy and environment, 3(1), 99108.

Maskan, A., Sevim, K. and Medeni, M. (2002) Hot air and sun drying of grape leather. Journal of food engineering, 54(1), 81-88.

Mustayen, A. G. M. B., Mekhilef, S. and Saidur, R. (2014) Performance study of different solar dryers: A review, 34, 463-470.

Nabnean, S., Janjai, S. Thepa, S., Sudaprasert, K., Songprakorp, R. and Bala. B.K. (2016) Experimtal performance of a new design of solar dryer for drying osmotically dehydrated cherry tomatoes. Renewable energy, 94, 147-156.

Osama, Y, Can, E. and Uzun.H.I. (2001) Mathematical modeling of thin layer solar drying of sultana grapes. Energy, 26, 457-465.
Ramadhani, B. R., Minja, J. A. and Karoli, N. N. (2014) Effect of glass thickness on performance of flat plate solar collectors for fruits drying. Journal of energy, Hindawi , article ID 247287, 1-8.

Saleh, A., and Badran. I. (2009). Modeling and experimental studies on a domestic solar dryer. Renewable energy, 34(10), 2239-2245.

Tunde-Akintunde, T. Y, and Afan. A. (2010). Modeling of hot -air drying of pretreated cassava chips. AgricEngInt: CIGR Journal, 12(2), 34-41.

Tunde-Akintunde, T.Y. (2011) Mathematical modeling of sun and solar drying of chilli pepper. Renewable energy, 36, 21392145.

Wang, C. Y., and Singh, R. P. (1978) A single layer drying equation for rough rice. ASAE Paper No.78-3001, St. Joseph, (MI). 